\title{
Assessoria jurídica universitária popular e a formação do bacharel em Direito
}

\author{
Public legal aid in the university and the education of the bachelor of Law
}

\author{
Damião Bezerra Oliveira* \\ Raphael Carmesin Gomes**
}

\section{Resumo}

O presente artigo visa a descrever as contribuições que o programa de extensão universitária Núcleo de Assessoria Jurídica Universitária Popular Aldeia Kayapó (Najupak) deu durante sua existência, para a formação do bacharel em Direito da Universidade Federal do Pará (UFPA). Para esse fim, além do referencial teórico que embasa as experiências e práticas da assessoria jurídica universitária popular (Ajup), exploram-se os discursos de bacharéis em Direito que, em algum momento de seu percurso formativo, participaram deste programa de extensão em seus 10 anos de existência (2004-2014). Nesse sentido, transcrevem-se as narrativas dos bacharéis, colhidas em entrevistas semiestruturadas, realizadas para a consecução da dissertação de mestrado apresentada ao Programa de Pós-Graduação em Educação da UFPA. Conclui-se que o Najupak foi essencial na promoção de uma formação paralela dos bacharéis em Direito, proporcionando a eles experiências pedagógicas diferenciadas do currículo oficial, por meio do estímulo às reflexões críticas sobre a própria formação jurídica.

Palavras-chave: Bacharel em Direito. Extensão universitária. Núcleo de assessoria jurídica.

\section{Abstract}

This paper aims at describing the contributions of the extension course Núcleo de Assessoria Jurídica Universitária Popular Aldeia Kayapó (NAJUPAK) in the academic education of Bachelors of Laws from the Federal University of Pará (UFPA). In order to achieve this end, the theoretical framework that guided procedures and experiences in the Academic Legal Aid Center were analyzed, as was the discourse of Bachelors in Laws that took part in this extension course at some point of their higher education, during its 10 years in activity (2004-2014). Thus, those former alumni's narratives were collected in semistructured interviews and transcribed for the elaboration of a dissertation for the attainment of a master's degree in the Education Postgraduate Program at UFPA. In conclusion, the NAJUPAK was essential to the promotion of a complementary academic training to the Bachelor of Laws, for it provided pedagogical experiences beyond those of the official curriculum that encouraged critical thought upon one's own juridical education.

Keywords: Academic center for legal aid. Bachelor of Laws. University extension course.

Recebido em 21/02/2018 - Aprovado em 21/06/2018

http://dx.doi.org/10.5335/rep.v25i3.8573

Doutor em Educação pela Universidade Federal do Pará (UFPA). Professor adjunto de Filosofia da Educação na mesma instituição. Integrante do corpo docente do mestrado em Educação e Cultura, UFPA campus de Cametá, e do Programa de Pós-Graduação em Educação, UFPA. E-mail: damiao@ufpa.br

** Bacharel em Direito pela Universidade Federal do Pará. Especialista em Filosofia da Educação e mestre em Educação na mesma instituição. E-mail: raphael.carmesin@gmail.com 


\section{Introdução}

É sempre importante compartilhar experiências de assessoria jurídica universitária popular (Ajup), principalmente quando essa prática se entremeia com as experiências formativas de gerações de bacharéis em Direito.

A prática jurídica sempre foi objeto de debate devido à sua importância para a formação jurídica. Recentemente, em 2017, foi promulgada a Resolução n⿳o 3, que alterou 0 art. $7^{\circ}$ da Resolução CNE/CES 9/04, estabelecendo doravante que os estágios supervisionados, enquanto componentes curriculares obrigatórios nos cursos de Direito, poderão ser realizados em outros espaços que não somente os Núcleos de Prática Jurídica (NPJ) vinculados às faculdades, como em órgãos do Poder Judiciário, escritórios de advocacia e serviços de assistência jurídica organizados e implantados pela instituição de ensino superior, o que abre espaço para que as experiências de Ajup tenham a sua institucionalidade mais fortalecida.

Diante do quadro atual, avulta a problemática em torno da formação do bacharel em Direito, tendo como ponto nodal a expansão do acesso ao ensino superior em tensão com a precarização da formação, por meio de um esvaziamento das funções de pesquisa e extensão nos cursos de Direito emergentes.

Daí a relevância de se analisar exemplos como o do Núcleo de Assessoria Jurídica Universitária Popular Aldeia Kayapó (Najupak), programa de extensão universitária que vigorou entre os anos de 2004 e 2014 no âmbito do curso de bacharelado em Direito da Universidade Federal do Pará (UFPA).

O Najupak, assim como as demais experiências de Ajup, consegue incitar, a um só tempo, reflexões em torno da extensão universitária e da formação jurídica. Essa convergência é natural, uma vez que a extensão universitária, enquanto dimensão indissociável do ensino e da pesquisa, faz parte do percurso formativo dos discentes, podendo ser uma práxis enriquecedora na vida dos futuros profissionais do Direito. Por essa relevância, propõe-se descrever as contribuições do Najupak durante sua existência, para a formação do bacharel em Direito da UFPA.

Se o Najupak não existe mais, as reminiscências em torno de sua prática ainda estão presentes na memória e na vivência de discentes e profissionais já formados, que, por meio de seu olhar, podem suscitar questionamentos e críticas relacionados ao ensino jurídico que se pratica, tendo como pano de fundo as suas próprias experiências enquanto extensionistas.

Dessa forma, o objetivo proposto exige a análise da experiência de extensionistas da UFPA vinculados ao Najupak em algum momento de seu percurso formativo, desde que conectada com um contexto maior de análises em torno da articulação entre extensão universitária e formação jurídica, relação que já vem sendo objeto 
de estudo sistemático de outros autores (MIRANDA, 2010; NORONHA, 2016; OLIVEIRA; MOURA; SANTOS, 2014; RIBAS, 2009).

Metodologicamente, este artigo adota uma abordagem qualitativa, consubstanciada em entrevistas individuais semiestruturadas, desenvolvidas a partir de um roteiro pré-definido com perguntas abertas, uma vez que se procuram respostas mais espontâneas, que deem conta de aspectos valorativos e compreensivos dos sujeitos entrevistados, captando outras dimensões do fenômeno (BONI; QUARESMA, 2005; FARR, 1982 apud BAUER; GASKELL, 2008; TRIVIÑOS, 1987).

A entrevista qualitativa possibilita, portanto, um enfoque fenomenológico do mundo da vida, uma vez que proporciona uma abertura entre o sujeito-pesquisador e o sujeito-pesquisado, por meio do encontro de outras interpretações e perspectivas do fenômeno investigado que se implicam continua e mutuamente (MASINI, 2000).

Antes de adentrar as narrativas dos discentes, é preciso se acercar, mesmo que sucintamente, das complexas práticas extensionistas da Ajup. Por isso, inicia-se com uma descrição histórica das práticas das Ajups, das suas teorias, dos desafios e limitações que enfrentam, para, então, aproximar-se da prática extensionista do Najupak e de suas especificidades. Posteriormente, a partir das falas dos discentes entrevistados, aborda-se a contribuição deste programa de extensão para a formação dos bacharéis em Direito da UFPA.

\section{A Ajup}

Tarefa muito complexa seria capturar a Ajup ${ }^{1}$ em um conceito. A sua formação histórica no Brasil bem como as suas muitas configurações e práticas ao longo das últimas décadas não podem ser apreendidas em um conceito, sem que restrinja a rica variedade de Ajups que surgiu surge e surgirá no seio das universidades brasileiras.

A Ajup não se fez, mas está se fazendo cotidianamente no período de formação de centenas de bacharéis em Direito que se inserem neste movimento, porque, se não é conceito, a Ajup pode ser considerada um movimento, cujo motor são os múltiplos fatores históricos e os variados marcos teóricos que a constituem.

Portanto, tudo o que se pode fazer são acercamentos deste movimento em uma tentativa de se dar um rosto para a Ajup, mesmo que ele se transforme e, tão logo seja descrito, mude de aparência.

A história demonstra que, pelo menos desde as décadas de 50 e 60 do século $\mathrm{XX}$, se tem registro de grupos que poderiam ser considerados precursores do que posteriormente passou a ser conhecido como Ajup: o serviço de assistência jurídica 
(Saju) da Universidade Federal do Rio Grande do Sul e o Saju da Universidade Federal da Bahia.

Tais grupos surgiram dentro de um contexto em que os estudantes buscavam se articular para desenvolver a prática forense ao lado das camadas populares, dentro de um processo de consolidação do acesso à justiça pelos mais pobres, iniciado pela Lei ํㅜㄹ 1060/50 (Lei da assistência judiciária gratuita) (ALMEIDA, 2015).

Com a efervescência e os embates políticos na época do regime ditatorial civil-militar no Brasil (1964-1985), os primeiros Sajus foram extintos. No âmbito das universidades, o protagonismo estudantil deu espaço a uma condução autoritária da estrutura universitária, fazendo com que muitas Ajups, forjadas dentro de uma concepção específica de extensão universitária, dessem lugar a núcleos de assistência jurídica.

Não obstante a oposição, foi nesse período de acirramento da violência e da repressão estatal que surgiram muitas experiências de assessoria jurídica popular, vinculadas a sindicatos, universidades, movimentos sociais e entidades em defesa dos direitos humanos (LUZ, 2008). Como exemplo, podem-se citar o Instituto Jurídico Popular, a Associação de Advogados de Trabalhadores Rurais da Bahia, o Gabinete de Assessoria Jurídica às Organizações Populares, entre outros (RIBAS, 2009).

Essa assessoria jurídica popular, reitera-se, apresenta uma polissemia e tem uma vasta complexidade de práticas.

A AJP [assessoria jurídica popular] vem se constituindo como polissêmica, seja compreendida como serviço legal [...], serviço legal inovador [...], práxis [...], orientação ideológica [...], prática jurídica insurgente [...] etc., seus significados se complementam na riqueza de experiências teórico-práticas que se identificam com a AJP (MARTINS, 2016, p. 69).

Foi no cadinho da dialética social, em meio a tensões concretas do processo de redemocratização e de movimentos emancipatórios de conquista de direitos, que a Ajup foi consolidando as suas experiências no âmbito universitário. As Ajups se desenvolveram, assim, no espaço acadêmico, tendo como protagonistas os estudantes de Direito e a sua articulação com a comunidade, diferenciando-se dos núcleos de prática jurídica tradicionais nos cursos de Direito (SEVERI, 2014).

Em um contexto mais amplo, as Ajups passaram a se aproximar dos movimentos sociais e das outras organizações vinculadas às classes populares a partir da crise do estado de bem-estar social, da ascensão das políticas neoliberais, bem como da retração dos movimentos de esquerda na década de 1980, os quais passaram a reorganizar as suas agendas sob outras pautas, como da cidadania, da democracia e dos direitos humanos (ALMEIDA, 2015). 
A partir da década de 1990, fortaleceram-se ainda mais as práticas jurídico-educativas das Ajups. Tais práticas visavam a dar conta das novas exigências para a formação jurídica que advinham da constitucionalização de direitos coletivos, da garantia de direitos humanos, da articulação de movimentos sociais na busca de alguma representatividade na democracia brasileira.

Tais exigências impulsionaram o questionamento do modelo tradicional de extensão universitária que preponderava nos cursos de direito do país e criticaram a relação entre o bacharel em Direito e a comunidade em que este se inseria (RIBAS, 2009).

\section{Conforme Furmann:}

Apesar da palavra "Assessoria", em sentido comum, ser quase sinônima da palavra "Assistência", foi ela escolhida para simbolizar uma metodologia inovadora de extensão. A escolha busca exprimir um significado político contrário às propostas de índole "assistencialista". A postura política da Assessoria, por surgir no espaço discursivo dos movimentos populares, é uma postura de contestação e não de caridade. Busca a Assessoria desconstruir o método assistencialista, contestar a sociedade da exploração do trabalho e rechaçar a Assistência como solução de problemas sociais (2003, p. 59).

Em 2014, pesquisa realizada na USP identificou 42 Ajups em atividade no Brasil. Tal pesquisa objetivou construir uma cartografia de experiências de extensão que ultrapassavam os moldes dos núcleos de prática jurídica, uma vez que envolviam mais do que aplicação técnica do Direito, constituindo-se em uma práxis pautada pela educação popular em direitos humanos (SEVERI, 2014).

$\mathrm{O}$ recrudescimento das experiências de Ajup pode ser creditado: à criação da Rede Nacional de Assessorias Jurídicas Universitárias (Renaju), no final da década de 1990, que organiza encontros, em âmbito nacional, para compartilhar experiências realizadas em todo o país; ao reconhecimento da extensão enquanto dimensão formativa do bacharel em Direito a ser desenvolvida nas instituições de ensino superior; e às reformas curriculares no curso de Direito, principalmente após 2004, que passaram a valorizar a prática jurídica e a indissociabilidade entre ensino, pesquisa e extensão (SEVERI, 2014).

A práxis das Ajups não veio descolada do que se consignou chamar teorias críticas do Direito. De fato, desde a década de 1960, as Ajups adotam como fundamento teórico para a orientação de suas práxis teorias diferenciadas daquelas preconizadas pela dogmática tradicional dos cursos de Direito, pautadas seja pelo jusnaturalismo, seja pelo positivismo jurídico. Tais concepções teóricas têm perspectivas em comum, a saber: 
a) a compreensão do Direito como instrumento de transformação social; b) o amplo acesso à justiça, visto não apenas como acesso ao Judiciário, mas sim abrangendo todos os meios legítimos para se alcançar a Justiça. Compreendendo, ainda, que o acesso à justiça deve significar um processo que busca a transformação do sistema de justiça acessado, e não apenas a inclusão nele, a partir de desenho político-institucional atual; c) o pluralismo jurídico comunitário-participativo, como projeto emancipatório dos novos sujeitos coletivos de direito, baseado nos valores de legitimidade, democracia, descentralização, participação, justiça, satisfação das necessidades, entre outros; e d) a educação popular como abordagem pedagógica para um processo libertador de conscientização (NORONHA, 2016, p. 235).

As experiências de assessoria jurídica universitária popular consideram o direito como um instrumento de transformação social, não a solução para todas as opressões e mazelas sociais, mas uma importante dimensão de lutas emancipatórias. Por isso, a Ajup tem uma ideologia, tomada neste trabalho como uma consciência prática voltada para a ação, para a práxis que situa o direito nos conflitos presentes na sociedade de classes (ALMEIDA, 2015).

Dessa maneira, "a identidade de assessoria passa, portanto, pela opção ideológica de estar ao lado dos trabalhadores e dos demais sujeitos subalternizados na sociedade de classes" (ALMEIDA, 2016, p. 189), e é isso que a diferencia de uma mera assistência jurídica nos moldes, por exemplo, dos núcleos de prática jurídica.

Assim, a Ajup provoca um "estalo", um "despertar ideológico" nos estudantes que vão se posicionando diante dos conflitos sociais e forjando uma compreensão de mundo a partir de sua práxis (ALMEIDA, 2016).

Todas as concepções teóricas que subjazem às experiências de Ajups, portanto, de alguma forma, são tomadas em favor do popular, em uma perspectiva denominada "crítica" do Direito, influenciada pelo marxismo. Segundo Diehl:

As principais referências teóricas que influenciaram a criação e o desenvolvimento destes grupos de assessoria estudantil foram a pedagogia do oprimido de Paulo Freire e o Direito Achado na Rua de Roberto Lyra Filho e José Geraldo Sousa Jr. (2009, p. 6).

Não cabe neste trabalho detalhar as múltiplas teorias críticas do Direito que influenciaram na construção de Ajups, que têm uma multiplicidade de riquezas teóricas e, inclusive, divergências entre si. Mas, por exemplo, na concepção do Direito Achado na Rua, os sujeitos são sujeitos sociais inseridos em espaços políticos de reconhecimento, negociação e criação de direitos em uma variedade de lutas por libertação (dos trabalhadores, das mulheres, dos refugiados, dos indígenas, etc.).

Da mesma forma, o amplo acesso à justiça, que não se esgota como acesso ao Judiciário, remete-nos ao "direito insurgente". Tal concepção parte do princípio de que há caminhos de lutas e emancipações pela via do direito positivado, estatal, desde que se leve em consideração que o direito é fecundado nas lutas sociais, nas demandas populares e, não raro, vai de encontro à juridicidade "oficial" (LUZ, 
2008). Cabe ao advogado popular ou ao bacharel em direito, na Ajup, abrir-se para o reconhecimento social e político deste saber, deste direito dos oprimidos (comunitário-participativo), por meio das categorias formais do direito positivo.

Essa cultura jurídica popular estaria calcada, também, no pluralismo jurídico que critica o esgotamento do projeto monista, que considera a identificação plena entre o direito, a lei e o Estado, e o monopólio deste último como fonte de juridicidade (WOLKMER, 2011).

As Ajups, em suas mais variadas atuações, até mesmo pelo referencial teórico que muitas vezes as acompanha (Lyra Filho, Boaventura Sousa Santos, Wolkmer, José Geraldo de Sousa Júnior, entre outros), deixam entrever em suas práxis a consideração e a legitimidade de direitos forjados na dinâmica dos movimentos sociais e não necessariamente a partir do que o Estado diz ser o direito. Isso, principalmente se tratando de práticas extensionistas, abre possibilidades para que 0 bacharel em Direito em formação reconheça que há um direito além dos manuais universitários, dos códigos de lei e dos discursos dos tribunais.

Ressalte-se, ainda, a influência do pensamento de Luís Alberto Warat, que propõe a aproximação entre o direito e outras formas de conhecimento (interdisciplinaridade), a fim de humanizá-lo, trazendo o afeto e a ludicidade para o interior do campo jurídico racionalizado, carnavalizando a pedagogia do Direito (WARAT, 2004a). O Najupak, por exemplo, sempre intentou inscrever as experiências sensíveis de seus participantes no mundo jurídico por meio de práticas estético-poéticas (teatro, música, poesia) nos termos da desconstrução epistemológica waratiana (WARAT, 2004b).

Mas, certamente, a relação entre a Ajup e a educação popular, que existe desde as primeiras experiências de assessoria, é fundamental (LUZ, 2008). A percepção majoritária das Ajups parece ser, inclusive, que "a educação popular contribui com a mobilização e organização coletiva dos indivíduos destinatários da assessoria popular em busca da efetivação ou reconhecimento de seus direitos" (SEVERI, 2014, p. 46).

Dessa forma, a Ajup tem um viés pedagógico e o pensamento freireano e a sua dialogia como matriz teórica entre bacharéis em Direito e os movimentos sociais ou as classes populares.

As AJUP's, através da pesquisa-ação, buscam realizar a extensão universitária como comunicação [...]: o processo de educação popular compreendido não como repasse mecanicista, dominador e antidialógico de conhecimentos, mas como coprodução de saber por sujeitos universitários e populares que o constroem na mesma medida em que constituem a si mesmos. Não se trata, pois, de a universidade educar ou conscientizar a comunidade, pois ninguém educa nem conscientiza ninguém; o processo é de conscientização conjunta [...] de educação que rompe com os muros universitários e se assume como prática de libertação na qual todos e todas são sujeitos criadores de conhecimento no bojo da luta por direitos (MEDEIROS, 2016, p. 134). 
Paulo Freire inspira, também, as categorias que compõem, no juízo de Almeida, o "quefazer" das Ajups, que são: "a educação popular, a horizontalidade, o protagonismo estudantil e a amorosidade” (2015, p. 39). A educação dialógica freireana, pautada pela busca de libertação e conscientização do sujeito, contrapõe-se à educação domesticadora que, conforme críticas correntes, tem dominado o ensino jurídico desde a sua origem.

De fato, a relação hierárquica estabelecida entre professores e discentes de Direito, bem como entre universitários e comunidade, tem forjado "operadores do direito", técnicos, quando muito, que são incapazes de perceber a sua formação enquanto práxis educativa, política, isto é, enquanto inserção crítica frente à realidade.

A presença do pensamento freireano, mesmo com as suas limitações e descontinuidades, instila no bacharel em Direito a formação do gosto pelo diálogo e pela "horizontalidade", tanto na organização interna da Ajup, quanto perante à comunidade. A horizontalidade serve como princípio condutor da prática da Ajup, uma vez que se caracteriza pelo respeito aos discursos e saberes de todos os que participam da construção coletiva das atividades dessa assessoria: do acadêmico ao lavrador, do estudante de ensino médio ao doutor em letras jurídicas.

Outro elemento que vem a reboque da prática da Ajup é o protagonismo estudantil, isto é, a inserção do bacharel em Direito como sujeito de sua própria formação. Não obstante as limitações oriundas da ausência de vinculação de professores universitários na condução e na orientação dos projetos realizados por Ajups, tal ausência da figura institucional acaba exigindo que os próprios participantes forjem o seu processo de aprendizado no espaço da extensão universitária (ALMEIDA, 2015).

Mas a extensão universitária é uma dimensão da universidade que não dá conta da complexidade das ações da Ajup. Ao contrário, a institucionalização universitária - consubstanciada em critérios para registro de projetos ou programas de extensão, bem como para seu financiamento -, acaba delimitando as ações da Ajup às dimensões avaliativas da extensão elaboradas pelo Fórum de Pró-Reitores de Extensão de Universidades Públicas do Brasil (Forproex) (SERRANO, 2001). Nesse sentido, os bacharéis em Direito participam da extensão universitária não nos moldes tradicionais, mas de uma perspectiva popular, crítica, herdeira do pensamento de Freire (1983).

Outro elemento presente nas coletividades em torno da Ajup é a amorosidade. Para Almeida (2015), tal amorosidade está relacionada à capacidade que a Ajup tem de mobilizar afetos, paixões, emoções por meio da ludicidade (poesia, teatro, dança, entre outras linguagens) e do estabelecimento de laços afetivos entre os seus mem- 
bros e deles com a comunidade. Esse aspecto nos remete à amorosidade, de Freire (1967), mas também à carnavalização do Direito, de Luís Alberto Warat (2004b).

Segundo Freire, "a educação é um ato de amor, por isso, um ato de coragem. Não pode temer o debate. A análise da realidade. Não pode fugir à discussão criadora, sob pena de ser uma farsa" (1967, p. 97). Através da amorosidade, Freire desvela que a relação pedagógica não se ensimesma em um quefazer científico, no sentido de neutro, racional e, por isso, insensível. Ao contrário, Freire defende que existe um mundo afetivo a ser conhecido em prol da luta política pela libertação dos oprimidos.

Nesse sentido, o encontro amoroso dos sujeitos possibilita a experiência educacional por excelência, qual seja, a abertura para o diálogo como exigência ética inarredável da relação entre os seres humanos. O diálogo, portanto, enquanto condição existencial, implica a amorosidade que possibilita o exercício da palavra de todos aqueles que, mediatizados pelo mundo, o pronunciem conjuntamente, humanizando-se mutuamente.

A educação popular, o protagonismo estudantil, a horizontalidade e a amorosidade podem também ser vistos no Najupak, analisado a seguir.

\section{A Najupak}

As atividades de extensão do curso de bacharelado em Direito da UFPA se limitaram, há décadas, a atividades de assistência jurídica, cujos exemplos marcantes foram o núcleo de prática jurídica, no campus de Belém, ainda em atividade, e o serviço de assistência jurídica e social, localizado no município de Castanhal. De fato, é como se a formação do bacharel em Direito da UFPA ignorasse os movimentos realizados nas outras regiões do país, no tocante às críticas feitas ao ensino jurídico bem como às mudanças em torno da política nacional de extensão.

Somente em 2004, na UFPA, surgiu o Najupak, na contramão de um ensino formalista, que se destaca por sua prática pedagógica positivista (MORAES, 2012), a partir do Encontro Nacional das Assessorias Jurídicas Universitárias, ocorrido durante o Encontro Nacional de Estudantes de Direito, em Belém, PA.

Como na formação de outras experiências de Ajup (ALMEIDA, 2015), o Najupak surgiu a partir do inconformismo de estudantes de Direito com o percurso que a sua formação acadêmica estava seguindo no âmbito da UFPA. Sob a impressão de que o curso de Direito se afastava sobremaneira da realidade circundante, o Najupak entreviu, nos espaços institucionais da extensão universitária, a possibilidade de aproximar-se dos movimentos sociais e da comunidade de uma forma geral (SANTOS; CAVALCANTE, 2014). 
No início, o grupo centrou-se em discussões e debates em torno da construção da Ajup que se queria, sua estrutura, suas atividades e seu perfil. Para esse fim, alguns discentes do curso de Direito se articularam em rede, antes da existência do Najupak, com estudantes de estados que já vivenciavam experiências de Ajup, como os representantes do Núcleo de Assessoria Jurídica Universitária Cosme Velho, do Maranhão, que auxiliaram, com oficinas de capacitação, a criação de uma Ajup na UFPA (SANTOS; CAVALCANTE, 2014).

Nesse ritmo, somente em 2006, o Najupak foi formalizado enquanto projeto de extensão, vinculando-se à Pró-Reitoria de Extensão (Proex) por meio do projeto Juventude Cidadã: conquistando direitos, sensibilizando deveres. A partir de 2007, o Najupak passou a ser parte da Renaju. Ao primeiro projeto somaram-se os projetos, em 2010, A Arte e a Não Exatidão da Matéria e, em 2011, Roda de Diálogos (SANTOS; CAVALCANTE, 2014). Com esses feitos, de projeto de extensão, o Najupak passou a ser um programa de extensão, isto é, um conjunto de projetos de extensão enfeixados.

Desde o início de suas atividades, o NAJUPAK atuou com questões relacionadas à efetivação de direitos de crianças e adolescentes e o projeto central desenvolvido pelo núcleo, o "Juventude Cidadã" teve diversas fases: 2007 a 2010, quando foi executado na escola José Alves Maia, localizada no bairro do Telégrafo, na cidade de Belém e tinha como foco principal a realização de oficinas com crianças do ensino fundamental da $5^{\underline{a}}$ à $8^{\underline{a}}$ série; em 2011 , continuou com o trabalho com crianças da mesma faixa etária, mas dessa vez atuando na escola Francisco Nunes, localizada no bairro do Guamá; em 2013, o núcleo voltou seu trabalho a estudantes a partir de 15 anos de quatro escolas públicas do bairro do Jurunas em Belém: EEEFM Prof Camilo Salgado, EEEFM David Salomão Mufarrej, EEEFM Profa. Placídia Cardoso e EEEFM Padre Benedito Chaves; finalmente, em 2014, o núcleo atua com estudantes de apenas uma das quatro escolas com as quais trabalhou em 2013, a escola Camilo Salgado (SANTOS; CAVALCANTE, 2014, p. 49).

Além da insatisfação com o ensino jurídico (ou em decorrência dessa insatisfação) e da atuação do movimento estudantil, outros fatores contribuíram para o surgimento do Najupak: o incremento das ações de pesquisa, caracterizado, principalmente, pela aproximação entre graduação e pós-graduação em Direitos Humanos com a criação do doutorado no Programa de Pós-Graduação em Direito e, consequentemente, com a reflexão (mesmo que incipiente) em torno do ensino jurídico na UFPA; a reformulação do projeto político-pedagógico do curso de Direito da UFPA em consonância com as diretrizes do Ministério da Educação, que criaram espaços para atividades extensionistas, as chamadas atividades complementares; e a articulação com o movimento estudantil e as suas reinvindicações (BERNARDO; MOURA, 2014).

Por meio de seu primeiro projeto, Juventude Cidadã: conquistando direitos e sensibilizando deveres, o Najupak já evidenciava as matrizes teóricas que iriam 
fundamentar a sua ação concreta, notadamente a educação popular calcada no pensamento de Paulo Freire.

Inicialmente, o projeto foi executado na Escola Estadual de Ensino Fundamental e Médio Prof. José Alves Maia. Como instrumental para a sensibilização dos alunos da rede pública quanto às violações cotidianas de direitos humanos, a Ajup realizava a educação popular por meio de atividades artísticas e lúdicas como teatro, fotografia e música -, o que revela uma certa contraposição aos meios mais tradicionais de transmissão de conteúdo, como a aula expositiva (WARAT, 2004a).

Todas as estratégias apontavam para um objetivo comum: o estabelecimento do diálogo entre os estudantes de Direito e os alunos das escolas públicas participantes, entre a universidade e parte da comunidade periferia de Belém, como forma de produzir conhecimento a partir da realidade concreta dos sujeitos, crianças e adolescentes (SANTOS; CAVALCANTE, 2014).

Primeiramente, o Najupak aplicava questionários entre os alunos das escolas participantes, a fim de conhecer a disponibilidade e os interesses dos possíveis sujeitos que vivenciariam as oficinas. Posteriormente, os membros do Najupak, pela observação dos participante e pela pesquisa-ação, começavam a interagir com as crianças e os adolescentes.

No entanto, sendo a educação popular freireana um processo que exige uma práxis criativa dos sujeitos de diálogo, que se alimenta dos desafios e limitações postos pela realidade concreta, muitas dificuldades existiram durante a execução do projeto Juventude Cidadã, como: a intensa rotatividade dos participantes do Najupak; a falta de estrutura logística nas escolas públicas participantes; a baixa participação do corpo discente das escolas; a inserção de uma hierarquia simbólica entre os acadêmicos de Direito e os alunos de ensino médio das escolas públicas (BERNARDO; SANTOS; SANTOS, 2014).

Em certo sentido, o Najupak foi uma Ajup focada, portanto, na educação popular em direitos humanos, não existindo uma atuação técnico-jurídica por parte do grupo, o que fomentou variadas discussões em seu interior (aliás, como ocorria em outras Ajups) sobre se o núcleo prestava uma assessoria jurídica ou se reduzia-se a uma experiência pedagógica (ALMEIDA, 2015).

Além das atividades extensionistas, cujo processo resulta do diálogo entre o conhecimento produzido na universidade e o conhecimento produzido na comunidade que vive, trabalha e produz fora do espaço universitário, o Najupak elaborou diversas intervenções no interior da UFPA, como os projetos Rodas de Diálogos e A Arte e a Não Exatidão da Matéria, cujo escopo era voltado para o público universitário, além de participar de reivindicações políticas nos espaços públicos da cidade. 
Uma das últimas ações do Najupak, em 2014, foi a organização do seminário Do Sonho ao Acontecer: 10 anos de Najupak, que culminou com a publicação de uma coletânea homônima de artigos de integrantes do núcleo, refletindo sobre a experiência acumulada de 10 anos no campo da educação popular em direitos humanos.

Entre os fatores para a desagregação do Najupak, podem-se citar: a perda do vínculo institucional com a Proex da UFPA e, consequentemente, do financiamento das bolsas de extensão; a saída de integrantes do núcleo, seja por ingressarem em outras frentes de atuação política, por encerrarem o seu ciclo de formação enquanto bacharéis, seja pelas demandas oriundas dos últimos anos de curso (trabalhos de conclusão de curso, prática jurídica, etc.); a falta de estrutura logística e de apoio do Instituto de Ciências Jurídicas da UFPA.

\section{A voz extensionista do bacharel em Direito}

O roteiro utilizado para entrevistar o extensionista do Najupak foi organizado em duas partes: a primeira se dedica à identificação do projeto pelo sujeito, isto é, a sua relação com o Najupak, como o identifica, como analisa a importância do núcleo para o curso de Direito da UFPA; já a segunda parte cinge-se à relação entre a concepção de direito que fundamenta a práxis do Najupak e a formação do sujeito entrevistado.

Tendo em vista ser exíguo o espaço dedicado a este artigo, não há como explorar todas as narrativas obtidas, configuradas em um farto material de análise. Mas pode-se citar algumas falas sugestivas, que esboçam a contribuição do Najupak para a formação do bacharel em Direito da UFPA.

Foram entrevistados 5 sujeitos $^{2}$ em cujo percurso formativo, em algum momento, o Najupak fez parte como atividade extensionista. A quantidade de entrevistas não foi aleatória, respeitou a saturação dos pontos de vistas que surgiram das narrativas, a fim de se evitar o esgotamento e a repetição de ideias, não obstante as diferenças de faixa etária e de tempo de conclusão do curso de bacharelado em Direito.

E1 estava no $9^{\circ}$ semestre, tendo participado do Najupak até a sua desagregação. E2 estava no $10^{\circ}$ semestre, tendo participado do Najupak até o fim de suas atividades. E3, atualmente, está vinculada ao Programa de Pós-Graduação (lato sensu) do Núcleo de Altos Estudos Amazônicos. E4 é mestre em Direito Agrário pelo Programa de Pós-Graduação em Direito da Universidade Federal de Goiás. E5 é advogada popular e professora de português. As múltiplas experiências dos participantes enriquecem as perspectivas.

Em se tratando de extensão universitária, está claro que há uma separação, na percepção das entrevistadas, entre o que consideram a extensão universitária 
tradicional e a extensão universitária popular, sendo esta preconizada de acordo com a pedagogia de Freire (1983). Nesse sentido,

[...] extensão universitária para mim, para além de instrumentos normativos e resoluções que existam sobre o tema, que a própria universidade sanciona, sempre teve um viés mais assistencialista. A extensão universitária como uma contrapartida de pesquisas e de atividades que a universidade desenvolve para a sociedade dá um sentido a uma expressão que é muito vaga que é a função social da universidade dentro de um contexto maior de comunidade local. Então, para mim, a extensão sempre se constituiu como uma forma do assistencialismo, entendendo a universidade como uma autarquia do Estado, como um espaço que congrega ações dos três poderes dentro do campus [...] então sempre me vem em mente, para além do discurso oficial, um viés mais assistencialista, e eu acredito que fazer extensão popular caminha no sentido oposto a esse assistencialismo; caminha no sentido de se colocar como assessor, como um educador popular, para utilizar a expressão do Paulo Freire, se colocar como alguém que escuta mais do que alguém que vai falar ou ensinar alguma coisa ou detém um determinado conhecimento, construindo ali com os sujeitos que estão envolvidos pelo processo educativo, que se constitui também como um espaço alternativo de pedagogia desse espaço pedagógico não escolar (E2).

É interessante a consciência que os sujeitos entrevistados têm com relação à discussão da extensão universitária no curso de Direito enquanto assistência jurídica e assessoria jurídica. Reproduzem, assim, um dilema histórico (ALMEIDA, 2015), presente nos debates travados na Renaju, que considera essa dicotomia como essencial para a atividade de uma Ajup.

Enquanto a assistência jurídica tradicional é uma prática fortalecedora do discurso individualista, patrimonial e positivista na formação do bacharel em Direito, característico dos núcleos de prática jurídica; a Ajup fomenta uma prática criativa, pois possibilita uma pedagogia inventiva que se alimenta dos desafios e limitações postos pela realidade concreta, dialeticamente conflituosa, por conceder ao estudante de Direito a possibilidade de compreender o fenômeno jurídico em relação ao seu contexto social mais amplo.

Ademais, ressalta-se o relato que aponta a presença inseparável do ensino, da pesquisa e da extensão na experiência no Najupak. As experiências de Ajup mobilizam a realidade concreta na formação do bacharel em Direito, e a realidade concreta não pode ser dissociada em espaços estanques de ensino, pesquisa e extensão: isso somente acontece na abstração.

Então esse é o Najupak . Ele é um projeto de extensão universitária, até na perspectiva mais ampliativa da extensão, que na época muita gente fazia o tripé como estanque: o ensino na sala de aula, a pesquisa nos livros e a extensão era só o repasse de informação. A gente entendia a extensão muito mais aproximada da práxis freireana de que... ao mesmo tempo que a gente ensina a gente aprende, faz pesquisa e extensão juntos. Então, a gente fazia extensão indo nas comunidades, fazendo trabalho, mas de lá a gente também fazia a pesquisa, então, os integrantes do Najupak publicaram vários artigos e TCCs dentro do mesmo trabalho (E5). 
O Najupak, como a maioria das experiências de Ajup, possibilitou a interdisciplinaridade entre ciências (psicologia, economia, direito, etc.) e entre saberes (saber dos universitários e saber das crianças e dos adolescentes), muito em vista da horizontalidade que norteava a prática extensionista do núcleo.

[...] quando a gente falava que era da universidade eles ficavam assustados, porque, para eles, às vezes, é que parecia estar muito distante a universidade dessas pessoas. Então, sempre olhavam a gente como se a gente tivesse em um posto acima deles e "caraca, vocês são da universidade? Vocês são do curso de Direito?". Tinha sempre uma dúvida, um questionamento, mas também perpassou por um processo de construção de confiança coletiva de eles poderem falar sobre temáticas que eles não tratavam em suas casas (E3).

A Ajup tem limitações com relação a possibilidade de ressignificar a realidade perante a coletividade com que se relaciona. Como disse E4: "a comunidade eu nem sei se se transforma tanto assim, mas com certeza o aluno se transforma muito mais".

O Najupak colocou em debate a própria concepção de universidade e a política extensionista da UFPA, notadamente do curso de Direito. Muito frequente, por exemplo, foi o relato, quase denunciativo, de que as atividades de extensão no curso de Direito se limitavam a atividades de pesquisa, restritas aos muros da universidade.

O que costumamos ver, normalmente, nos projetos de extensão é que a realidade tem mudado um pouco nos últimos anos, mas, normalmente, os projetos de extensão, mesmo sendo de extensão, têm um corpo muito mais de pesquisa, se restringindo ou à pesquisa bibliográfica - fazendo levantamento bibliográfico, etc. -, ou tem um campo de atuação que ainda é restrito à universidade $(\mathrm{E} 1)$.

Quanto ao curso de Direito mais especificamente, o Najupak nasceu em uma época em que a institucionalização da extensão na UFPA, via Forproex, estava em seu início, logo, poucos projetos ou programas de extensão estavam registrados e consolidados. No caso do Najupak, sendo uma atividade interdisciplinar com múltiplas ações, os entrevistados relataram as dificuldades que tiveram em adaptar as atividades do núcleo dentro dos indicadores propostos pela Proex (relatórios, produtos de extensão, parâmetros de avaliação, etc.), além das dificuldades estruturais (orçamentárias e de espaço físico). 
[...] a gente encontrou também muita dificuldade, ao longo desses 10 anos, de se constituir, por conta de orçamento, para desenvolver as atividades. Apesar de enxergar como crescente essas políticas de valorização da extensão universitária, elas estão muito aquém da valorização que existe para com a pesquisa universitária. Existe uma hierarquia dentro da universidade muito grande, então é difícil conseguir auxílio para o desenvolvimento dessas atividades, ainda mais uma extensão que não vai trazer resultado quantitativo para universidade, mas vai trazer resultado social para comunidade, então, acredito que essa relação ambígua que a gente tem para com o que é institucional, para com o que é gerenciar ou para com o que é burocrático. Ao mesmo tempo que a gente entende a importância da disputa desses espaços, a gente encontra uma série de dificuldades para conciliar visões com eles, então acho que essa é a principal limitação do Najupak (E2).

Essa dificuldade em se adequar aos parâmetros institucionais foi um dos obstáculos encontrados pelo Najupak para manter o acesso a bolsas de extensão e, por conseguinte, o funcionamento regular das atividades. Algo muito presente na fala dos sujeitos, portanto, foi a desvalorização da extensão enquanto atividade acadêmica séria, que enriquece a pesquisa e o ensino por meio do contato com a comunidade.

Quanto à formação em bacharelado em Direito, as entrevistadas frisaram pontos que já foram ressaltados anteriormente: o protagonismo estudantil na construção da Ajup (ALMEIDA, 2015), o estabelecimento de uma distinção entre a formação proporcionada pelo curso de Direito da UFPA e uma formação paralela, realizada a partir das experiências no Najupak: uma verdadeira Paideia (LUZ, 2008).

[...] eu considero fundamental o papel que o Najupak teve para a minha formação. Uma importância de me fazer enxergar a mim mesma como um sujeito desses debates e dessas lutas e não tanto assim para a minha formação profissional estrita. O fato do Najupak ter possibilitado um contato meu com categorias sociais e com movimentos sociais e populares fez com que eu me organizasse também em movimentos sociais e populares e entendesse bandeiras e lutas como minhas bandeiras e lutas também (E2).

É provocativo este termo usado por uma das entrevistadas quanto ao espaço de atuação do Najupak em relação ao curso de Direito da UFPA: "gueto de suspiro e até de inconformação" (E5). Um gueto sugere a ideia de isolamento, de estabelecimento de fronteiras por causas externas adversas. De certa forma, o Najupak viveu uma relação conflituosa com a estrutura institucional do curso de Direito da UFPA, uma "disputa do espaço institucional e da ideologia do curso" (E2). 
Existia um grande contraponto que nós costumávamos fazer dentro da universidade no curso de Direito, e isso não escapou à crítica à grade curricular do ensino de Direito, não escapou da gente fazer essa crítica, da gente implementar essa crítica... a nossa formação é uma formação prioritária voltada para disciplinas. A gente tem uma grade curricular voltada muito mais para uma dogmática do direito, ou seja, em que a gente tem a lei como fonte, e tem muitos manuais falando sobre as leis, explicando a lei, dizendo sobre a lei. Óbvio que o Najupak desempenhou funções na minha formação enquanto bacharela de Direito, porque foi uma militância dentro desse processo, e isso foi desenhando também os meus caminhos. Por exemplo, o fato de hoje eu ter um objetivo de ser professora universitária também vem das formações que tive no núcleo, da concepção que o núcleo conseguia me apontar em relação ao direito e quais as características que uma operadora do direito deveria ter, além das características que eu não gostaria de ter dentro do curso Direito. Uma dessas características era ser uma profissional que reproduzisse ou colocasse um direito na sala de aula que não trouxesse a emancipação de consciências (E3).

A princípio, podem-se distinguir dois tipos de formação: por um lado, a formação oficial, proporcionada pela instituição universitária, com seu percurso curricular, seu quadro docente, suas normatizações, seu espaço e sua logística, voltada para a formação técnico-profissional, de cunho liberal, individualista, pautada pelo positivismo jurídico, pela leitura de manuais de direito e livros mais técnicos (MORAES, 2012); e, por outro, os sujeitos que vivenciaram as experiências do Najupak tiveram contato com a crítica que se faz ao ensino jurídico desde, pelo menos, a década de 1970, principalmente por meio do Direito Achado na Rua, propugnado por Roberto Lyra Filho (LUZ, 2008). Da mesma forma, as leituras em torno de Paulo Freire e de outras correntes ditas críticas do Direito despertaram o inconformismo com a própria formação.

A dificuldade era de formar essas novas pessoas para atuar em assessoria jurídica popular, porque não é uma formação simples, só fazer relatório, estabelecimento de dados e sistematizar, é uma formação que mexe com a nossa formação pessoal, de perspectiva, entendimento de vida, de reconhecimento, de identidade (E1).

Ao ser inserido no Najupak, o bacharel em Direito se via imerso em um processo formativo para assumir-se enquanto sujeito e protagonista de sua própria formação. Esta formação perpassava pela discussão, rodas de diálogo e debates em torno de temas secundarizados no curso de bacharelado em Direito, como questões de gênero, de diversidade sexual, o extermínio da juventude negra, a questão agrária, a reforma constitucional, entre outros temas relembrados pelas entrevistadas.

Os ajupianos ${ }^{3}$ também iniciavam um contato com autores não tão populares nas ementas disciplinares do percurso curricular oficial, como Boaventura de Sousa Santos, José Geraldo de Sousa Júnior, Roberto Lyra Filho, Luis Alberto Warat, Paulo Freire, Carlos Wolkmer, Thomaz Pressburger, Karl Marx, Antonio Gramsci, 
entre outros, que compõem uma ampla diversidade de vertentes teóricas que pensam o direito, a educação, a sociedade a partir de outros vieses.

Outro fator que se percebe relevante nas entrevistas é a ideia de que a vivência no Najupak deu novas perspectivas profissionais aos discentes. E1, por exemplo, critica o lugar comum do discente de direito: aquele que sonha com ascensão social por meio do recebimento de vultosos salários, oriundo de cargos públicos rentáveis (magistratura, procuradorias, promotorias, etc.) ou de uma carreira bem-sucedida na advocacia; que não tem consciência de sua importância, enquanto sujeito, para a construção de uma sociedade mais equitativa; que não se posiciona ideologicamente ao lado das classes sociais trabalhadoras, mas reproduz uma visão elitista do direito.

Não poucas vezes ouvimos das entrevistadas que o Najupak tornou interessante outros caminhos profissionais, como o da advocacia popular ou do magistério superior, fazendo um verdadeiro contraponto àqueles discentes que, em sua formação, vivenciaram os espaços tidos por tradicionais nos cursos de Direito (estágios em escritórios de advocacia e órgãos públicos), mediante o desenvolvimento de algumas características: o protagonismo estudantil (ALMEIDA, 2015); a capacidade de fazer uma releitura da dogmática jurídica; a habilidade de pensar interdisciplinarmente; e a abertura para o diálogo e para o trabalho coletivo.

A ambígua relação entre a formação oficial e a formação preconizada no âmbito do Najupak gerou uma dificuldade constante para a existência do núcleo, o que contribuiu, inclusive, para a sua desagregação: a dificuldade em equilibrar as atividades oriundas das disciplinas acadêmicas (provas, estágios, atividades complementares, etc.) com as atividades originadas na Ajup (oficinas, rodas de diálogo, debates, etc.).

[...] eu acho que um grande problema nosso, assim, enquanto organização, o que me dói muito, que acabou tudo ou deu uma pausa, não sei, mas é de que a gente não consegue atuar em diversas frentes, isso para mim é muito claro. Eu, por exemplo, fazia pesquisa na universidade então já estava aqui. Então, eu conseguia fazer pesquisa e extensão, porque já estava vivendo aqui, mas você não consegue participar do Najupak, participar da política, participar de mil atividades, acho que uma grande lacuna que acompanha a gente desde o princípio é essa (E4).

Em algum momento de sua formação, o discente tinha que escolher entre concluir o curso de graduação, satisfazendo as obrigações do percurso curricular oficial, e realizar as atividades do Najupak, que demandavam tempo e esforços consideráveis, dado o protagonismo estudantil, algo ínsito à Ajup. 


\section{Considerações finais}

Historicamente, a extensão universitária no âmbito do curso de Direito foi pautada por uma prática repetitiva, na qual se sobressaem a extensão como uma prestação de serviços assistencial - em núcleos de prática jurídica, em sua maioria - e o direito como um instrumento de pacificação das relações individuais, voltado para o treinamento da técnica jurídica, isto é, para a manipulação dos institutos jurídicos forjados por um direito liberal, individualista e patrimonial.

Dentro dessa prática petrificada, pouco ou nenhum espaço foi dado à problematização da própria formação jurídica, ou seja, aqueles que vivenciaram essa experiência extensionista não tinham contato com a crítica que se fazia - desde, pelo menos, a década de 1950 - ao ensino jurídico praticado nas universidades brasileiras, tampouco tinham o espaço institucional formativo para refletir sobre o próprio Direito que se ensinava, suas variadas concepções e abordagens epistemológicas.

A partir da década de 50 do século XX, surgiu uma tradição de experiências extensionistas que podemos considerar fundamental para a formação do bacharel em Direito: as experiências de Ajup. No caso da UFPA, o Najupak foi um programa de extensão que assumiu para si a função de ser uma assessoria jurídica universitária popular e que surgiu a partir dos clamores estudantis para uma formação mais prática, que possibilitasse o contato dos discentes com os problemas sociais mais candentes.

O Najupak, não obstante as suas limitações e contradições internas, foi um verdadeiro contraponto à formação jurídica preconizada pelo curso de bacharelado em Direito da UFPA. Enquanto o currículo oficial do curso configurava-se em torno de disciplinas jurídicas estanques da tradicional dogmática jurídica, do positivismo jurídico, das aulas-conferências, o Najupak possibilitava aos discentes experiências educativas diferenciadas, evocando temáticas, autores e metodologias de ensino singulares.

As narrativas em torno do Najupak o compreendem como um mobilizador de estudos e discussões que possibilitam uma "consciência da realidade" (E1) mais aprofundada, que vai além das percepções tradicionais do que é o Direito e para o que ele serve. A Ajup propiciou, portanto, experiências formativas - por meio da extensão universitária - que foram além das aulas-conferências, principal metodologia de ensino do curso de Direito desde a sua fundação no país.

Os discentes do Najupak saíam das salas de aulas, das aulas-conferências, e aprendiam a debater e a sugerir as suas próprias pautas, estudando temáticas como direitos humanos, reforma agrária, gênero, racismo na periferia, democrati- 
zação da universidade, entre outros assuntos não frequentes na prática pedagógica do curso de Direito da UFPA.

Autores que analisavam o Direito de outras perspectivas, a partir da sociologia jurídica, da filosofia, da pedagogia - Direito Achado na Rua, direito insurgente, pluralismo jurídico, direito alternativo, educação popular, etc. -, eram estudados, além dos manuais jurídicos comuns dentro das salas de aulas do curso.

Em se tratando de extensão universitária popular, o Najupak legou como características virtuosas para a formação do bacharel em Direito as capacidades de compreender a horizontalidade no processo pedagógico, de ser protagonista de sua própria formação (protagonismo estudantil) e de praticar a amorosidade, de acordo com o pensamento freireano.

Essas características revelam uma postura comum entre esses discentes, qual seja, a de estarem conscientes de que fazer parte de uma Ajup é fazer parte de um embate ideológico no seio das faculdades de Direito, tomando partido das classes trabalhadoras e de demais sujeitos subalternizados na sociedade conflituosa em que vivemos.

O discurso sobre a desmistificação do direito, muito propagado pelos profissionais egressos da Paideia ajupiana, se faz presente também na postura desses profissionais, que se abrem para o contato com movimentos sociais e outras coletividades subalternizadas, as quais, seja pelo desconhecimento do direito (o que inclui a linguagem jurídica, os ritos, os processos, etc.), seja pela mobilização social precária, estão excluídas da capacidade legítima de lutar por seus direitos.

A proximidade com os problemas sociais mais candentes - seus conflitos, lutas por direitos, opressões de toda sorte - fez com que o discente de Direito, uma vez lançado ao mercado de trabalho, tivesse mais inclinação a olhar a si próprio e a sociedade como um espaço de luta por direitos e de defesa contra as violações de direitos humanos sofridas por grupos subalternizados, tendo como "estalo" inicial (ALMEIDA, 2015) as experiências na Ajup.

\section{Notas}

1 Para fins deste artigo, Ajup não é denominação de um núcleo de prática jurídica, nem de um projeto de extensão, mas de um movimento nacional de práxis de bacharéis em Direito, que se identifica posicionado criticamente ao lado dos trabalhadores e dos demais sujeitos subalternizados na sociedade de classes e que apresenta um referencial teórico específico, conforme demonstrado no texto.

2 Os sujeitos entrevistados não têm seus nomes revelados por questões ético-jurídicas, assumidas em termo de consentimento livre e esclarecido, sendo identificados doravante, tão somente, como E1, E2, E3, E4 e E5.

3 Designação muito utilizada nas entrevistas para denominar aqueles que vivenciaram as experiências nas Ajups. 


\section{Referências}

ALMEIDA, A. L. V. Junto aos esfarrapados do mundo: a educação popular da Assessoria Jurídica Universitária Popular. Revista Insurgência, Brasília, a. 2, v. 2, n. 2, p. 159-193, jul./ dez., 2016.

Um estalo nas Faculdades de Direito: perspectivas ideológicas da Assessoria Jurídica Universitária Popular. 2015. 340 f. Tese (Doutorado em Direito)-Programa de Pós-Graduação em Ciências Jurídicas, Universidade Federal da Paraíba (UFPB), Paraíba. 2015.

BERNARDO, C. C.; MOURA, A. P. Najupak: 10 anos construindo educação popular. In: OLIVEIRA, A; MOURA, A; e SANTOS, J. C. Do sonho ao acontecer: 10 anos de Najupak. Belém: Proex-UFPA, 2014. p. 59-71.

BERNARDO, C. C.; SANTOS, J. C. B. M; SANTOS, S. R. Projeto juventude cidadã: experiências a partir da educação popular em direitos humanos na escola Francisco Nunes, Guamá/Belém. In: OLIVEIRA, A; MOURA, A; e SANTOS, J. C. (Org.). Do sonho a a acontecer: 10 anos de Najupak. Belém: Proex-UFPA, 2014. p. 86-98.

BONI, V.; QUARESMA, S. J. Aprendendo a entrevistar: como fazer entrevistas em ciências sociais. Em Tese, Florianópolis, v. 2, n. 1, p. 68-80, jan. 2005.

BAUER, M.; GASKELL, G. Pesquisa qualitativa com texto, imagem e som: um manual prático. Rio de Janeiro: Vozes, 2008.

DIEHL, D. A. Metodologia da assessoria jurídica popular na luta pela realização histórica dos direitos humanos. In: ENCONTRO ANUAL DA ASSOCIAÇÃO NACIONAL DE DIREITOS HUMANOS, PESQUISA E PÓS-GRADUAÇÃO (ANDHEP). 5., 2009, Belém, PA. Anais... Belém: ANDHEP, 2009. p. 1-19.

FREIRE, P. Educação como prática de liberdade. Rio de Janeiro: Paz e Terra, 1967. Extensão ou comunicação? Rio de Janeiro: Paz e Terra, 1983. . Pedagogia do oprimido. Rio de Janeiro: Paz e Terra, 1987.

FURMANN, I. Assessoria jurídica universitária: da utopia estudantil à ação política. 2003. $96 \mathrm{f}$. Monografia (Curso de Bacharelado em Direito) - Faculdade de Direito, Universidade Federal do Paraná (UFPR), Curitiba, 2003.

LUZ, V. C. Assessoria jurídica popular no Brasil. Rio de Janeiro: Lumen Juris, 2008.

MARTINS, M. P. M. J. O Direito através do espelho: contribuições da assessoria jurídica popular às lutas de movimentos populares em torno do direito à terra e ao território. Revista Insurgência, Brasília, a. 2, v. 2, n. 2, p. 51-79, jul./dez. 2016.

MASINI, E. F. S. Enfoque fenomenológico de pesquisa em educação. In: FAZENDA, I. (Org.). Metodologia da Pesquisa Educacional. São Paulo, SP: Cortez, 2000. p. 59-67.

MIRANDA, C. Na práxis da assessoria jurídica universitária popular: extensão e produção de conhecimento. 2010. 156 f. Dissertação (Mestrado em Direito)-Programa de Pós-Graduação em Ciências Jurídicas, Universidade Federal da Paraíba (UFPB), João Pessoa, PB, 2010. 
MORAES, E. A. S. A educação jurídica positivista e as diretrizes do ensino jurídico: currículo e práticas pedagógicas no curso de Direito da UFPA no horizonte das competências e habilidades. 2012. 191 f. Tese (Doutorado em Direito)-Universidade Federal do Pará (UFPA), Belém, PA, 2012.

NORONHA, E. C. A Assessoria jurídica universitária popular como uma proposta contra hegemônica à educação jurídica tradicional. Revista Insurgência. Brasília, a. 2, v. 2, n. 2, p. 220-243, jul./dez. 2016.

OLIVEIRA, A; MOURA, A; SANTOS, J. C. Do sonho ao acontecer: 10 anos de Najupak. Belém: Proex-UFPA, 2014.

RIBAS, L. O. Direito insurgente e pluralismo jurídico: assessoria jurídica de movimentos populares em Porto Alegre e no Rio de Janeiro (1960-2000). 2009. 148 f. Dissertação (Mestrado em Filosofia e Teoria do Direito)-Programa de Pós-Graduação em Direito, Universidade Federal de Santa Catarina (UFSC), Florianópolis, Santa Catarina, 2009.

SANTOS, J. C. B. M dos; CAVALCANTE, Breno N. S. Najup Aldeia Kayapó: 10 anos em defesa dos direitos humanos. In: OLIVEIRA, A; MOURA, A; e SANTOS, J. C. Do sonho ao acontecer: 10 anos de Najupak. Belém: Proex-UFPA, 2014. p. 48-58.

SERRANO, R. M. S. M. et al. Avaliação nacional da extensão universitária. Brasília: MEC/Sesu; Paraná: UFPR; Ilhéus: UESC, 2001. (Coleção Extensão Universitária v. 3. Fórum de Pró-Reitores de Extensão das Universidades Públicas Brasileiras.).

SEVERI, F. C. Cartografia social e análise das experiências de assessorias jurídicas universitárias populares brasileiras: relatório de pesquisa. Ribeirão Preto: Faculdade de Direito de Ribeirão Preto, 2014.

TRIVIÑOS, A. N. S. Introdução à pesquisa em ciências sociais: a pesquisa qualitativa em educação. São Paulo: Atlas, 1987.

WARAT, L. A. Epistemologia e ensino do Direito: o sonho acabou. Florianópolis: Fundação Boiteux, 2004a.

. Territórios desconhecidos: a procura surrealista pelos lugares do abandono e da reconstrução da subjetividade. Florianópolis: Fundação Boiteux, 2004b.

WOLKMER, A. C. Pluralismo jurídico: fundamentos de uma nova cultura no Direito. São Paulo: Alfa Omega, 2001. 